\title{
Application of CareDose 4D combined with Karl 3D technology in the low dose computed tomography for the follow-up of COVID-19
}

Jiawei $\mathrm{Li}^{1+}$, Xiao Wang ${ }^{1 \dagger}$, Xiaolu Huang ${ }^{1}$, Fangxing Chen ${ }^{1}$, Xuesong Zhang ${ }^{1}$, Ying Liu ${ }^{2}$, Guangzuo Luo ${ }^{3^{*}}$ (D) and Xunhua $\mathrm{Xu}^{1 *}$

\begin{abstract}
Background: Coronavirus disease 2019 (COVID-19) is a highly infectious disease caused by the new coronavirus. Previous studies have shown that the chest $\mathrm{CT}$ examination plays an important role in the diagnosis and monitoring of COVID-19. However, some patients with COVID-19 had low white blood cell counts and reduced lymphocyte ratios. Multiple CT examinations may cause radiation damages as well as increase the apoptosis of peripheral blood lymphocytes. A new low-dose CT method should be developed because the regular CT may aggravate the disease.
\end{abstract}

Method: Sixty cases were randomly divided into the study group $(n=30)$ and control group $(n=30)$. The lung window was reconstructed by Karl 3D iterative technique in the study group. The image quality was subjectively evaluated by two senior chest group diagnostic physicians using a 5-point double-blind method. The value of CT measurement and its standard deviation (SD) was used as an objective evaluation criteria. The volume of CT dose index (CTDI vol $)$, dose length product (DLP) and effective dose (ED) from the two groups were compared and analyzed statistically.

Result: There was no significant difference in the occurrence rates of ground glass opacities, consolidation, crazypaving pattern, fiber cable shadow and axial interstitial thickening between the study group and control group $(p>0.05)$. In addition, no significant difference was found for the subjective score of overall image quality and image noise level (SD) between the two groups $(p>0.05)$. However, significant differences was found in $C T D I_{\text {vol, }}$ DLP, and ED between the study group and the control group $(p<0.05)$. The effective dose of the study group was reduced by $76 \%$ compared to the control group.

(Continued on next page)

\footnotetext{
*Correspondence: gzluo@cmu.edu.cn; xxhwh@163.com

${ }^{\dagger}$ Jiawei Li and Xiao Wang contributed equally to this work.

${ }^{3}$ Institute of Translational Medicine, China Medical University, Shenyang 110122, China

'Department of Radiology, China Resources \& WISCO General Hospital, Wuhan 430080, China

Full list of author information is available at the end of the article
}

(C) The Author(s). 2020 Open Access This article is licensed under a Creative Commons Attribution 4.0 International License, which permits use, sharing, adaptation, distribution and reproduction in any medium or format, as long as you give appropriate credit to the original author(s) and the source, provide a link to the Creative Commons licence, and indicate if changes were made. The images or other third party material in this article are included in the article's Creative Commons licence, unless indicated otherwise in a credit line to the material. If material is not included in the article's Creative Commons licence and your intended use is not permitted by statutory regulation or exceeds the permitted use, you will need to obtain permission directly from the copyright holder. To view a copy of this licence, visit http://creativecommons.org/licenses/by/4.0/ The Creative Commons Public Domain Dedication waiver (http://creativecommons.org/publicdomain/zero/1.0/) applies to the data made available in this article, unless otherwise stated in a credit line to the data. 
(Continued from previous page)

Conclusion: CareDose 4D low-dose scanning combined with Karl 3D iterative reconstruction technology can not only greatly reduce the radiation dose, but also provide images that meet the diagnostic criteria of COVID-19, which can be used as a routine method for the follow-up of COVID-19 patients.

Keywords: COVID-19, Radiation dose, CareDose 4D, Image quality

\section{Background}

Coronavirus disease 2019 (COVID-19) is a highly infectious disease caused by the new coronavirus [1, 2]. Timely and effective intervention can improve the success rate of treatment of critically ill patients [3]. We believe imaging examination is the main method for clinicians to understand the progress of the disease. Previous studies have indicated that the chest $\mathrm{CT}$ examination plays a important role in the diagnosis and monitoring of COVID-19. However, some patients with COVID-19 had low white blood cell counts and reduced lymphocyte ratios [4]. Multiple CT examinations may cause radiation damages as well as increase the apoptosis of peripheral blood lymphocytes [5]. In this study, we have explored the application of low-dose chest CT scans in the follow-up of patients with COVID-19 using Care Dose 4D combined with Karl's 3D iterative reconstruction technology compared with conventional-dose chest CT.

\section{Methods}

\section{General materials}

Fifty-six patients with common COVID-19 diagnosed in our hospital from February 17, 2020 to March 4, 2020 were selected, including 29 males and 27 females aged 32 to 86 years with an average age of $(61.9 \pm 13.7)$ years. CT scan was performed within 2-3 weeks after diagnosis. All cases with body mass index (BMI) in the range of $18.5 \sim 24.9 \mathrm{~kg} /$ $\mathrm{m}^{2}$ were randomly divided into a study group and a control group with 30 cases in each group (4 patients from the two groups had two CT follow-ups performed by the same patient at different times). There were 17 males and 13 females in the study group, aged 38 to 81 years with an average age of $(61.6 \pm 12.6)$ years. There were 13 males and 17 females in the control group, aged 32 to 86 years, with an average age of $(62.2 \pm 15.0)$ years. Inclusion criteria: (1) at least one positive test of the new coronavirus nucleic acid; (2) complete clinical data and CT thin-layer images of the chest. Exclusion criteria: (1) patients with underlying lung diseases, such as lung tumors, tuberculosis, and other infections in the lungs; (2) patients could not cooperate for some reason, which led to blurred CT images.

\section{Inspection method}

The equipment used for lung scan is a 40-row multislice spiral CT (uCT530, United Imaging, Inc., China).
For CT inspection, the patient was in a supine position, with both hands raised above the head. The scans were performed from the apex of both lungs to the diaphragm on both sides when the breath of the patients was hold at the end of deep inhale. CareDose 4D technique and filtered back projection(FBP) algorithm image reconstruction were used in both groups. The fixed tube current of the two groups was $120 \mathrm{kV}$. The reference tube currents of the study group and the control group were $30 \mathrm{mAs}$ and $130 \mathrm{mAs}$, respectively. The scan matrix was $512 \times 512$, with $5 \mathrm{~mm}$ of layer thickness, $5 \mathrm{~mm}$ of layer spacing and 1.0725 of pitch. The image reconstruction layer thickness was $1 \mathrm{~mm}$ and the layer spacing was $0.8 \mathrm{~mm}$. The lung window of the control group was reconstructed with routine reconstruction method, while the study group was reconstructed using Karl 3D level 3 iterative technology. The KARL Iterative Reconstruction technique is designed to perform both in the projection (raw data) space and the image space for uCT family systems. Starting in projection space, KARL detects signals that are likely to contribute to image artifacts. Once the signals are selected, their noise level will be estimated based on photon statistics. Then the projection data will be iteratively processed by penalizing the selected noise data according to the noise model, and artifacts would be significantly suppressed while edge information is still preserved.

\section{Image evaluation}

The personal information, scan parameters and dose of the patients were hidden in the PACS system. The images were evaluated by two senior chest diagnosticians using double-blind method at fixed window position and width. The parameters for lung window are $-600 \mathrm{HU}$ of position and $1200 \mathrm{HU}$ of width. The parameters for mediastinal window are $40 \mathrm{HU}$ of position and $350 \mathrm{HU}$ of width. The image quality of ground glass opacities (GGO) and crazy-paving pattern were scored subjectively according to the 5-point scale evaluation system.

\section{Subjective evaluation}

Five-point scale system was used to evaluate the images (Table 1). A score of 3 or more is considered to meet diagnostic requirements. In case of the two physicians do not agree on the score, they will reach an agreement through consultation. 
Table 1 Subjective evaluation standard of 5-point system

\begin{tabular}{lll}
\hline Score & GGO & Crazy-paving pattern \\
\hline Five points & clear & clearly visible \\
Four points & clear & visible \\
Three points & visible & unclear \\
Two points & visible & blurred \\
One point & non-visible & unclear \\
\hline
\end{tabular}

\section{Objective evaluation}

The CT values were measured and standard deviation (SD) was calculated for an area of about $1 \mathrm{~cm}^{2}$ area of interest (ROI) in the central area of the descending aorta at the tracheal carina layer. The volume of CT dose (CTDIvol) and the dose length product (DLP) were automatically given by the recording system, which were used to calculate the effective dose (ED), ED $=\mathrm{DLP} \times \mathrm{k}$ (chest $\mathrm{k}=0.014)$.

\section{Statistical analysis}

The SPSS 17.0 statistical software is used for statistical analysis. All quantitative data are expressed as $\mathrm{x} \pm \mathrm{s}$, and qualitative data are expressed as percentages. The independent sample $t$-test was used to measure the differences in subjective quality scores, CT values of descending aorta, SD of image noise, CTDIvol, DLP and ED of the images between the control group and the study group. The incidence rates of GGO, consolidation, crazy-paving pattern, fiber cable shadow and central axis interstitial thickening between the two groups were compared using the $\mathrm{x}^{2}$ test. $p<0.05$ was considered statistically significant.

\section{Results}

\section{Comparison of the CT signs}

The number of cases with multiple lesions in the study group and control group are 26 and 24, respectively. There were 4 cases with diffusely distributed CT sign in the study group and 6 case in the control group. For cases with mainly subpleural distribution, the number is 28 and 25 for the study group and control group, respectively. There were 2 cases in the study group and 5 cases in the control group were distributed along the bronchial vascular bundle. The main signs of the two groups (Fig. $1 \mathrm{~A} \sim \mathrm{F}$ ) include GGO, crazy-paving pattern, consolidation and fiber cable shadow. A few patients may have axial interstitial thickening. There were no statistical differences in the occurrence rate of the above signs between the two groups $(p>0.05$, Table 2$)$.

\section{Comparison of image quality}

The subjective overall image quality score of the study group was $3.97 \pm 0.81$, which was not significantly different from that $(4.27 \pm 0.78)$ of the control group $(p>$
0.05). We also did not found significant difference in CT value and SD of descending aorta between the control group and the study group $(p>0.05$, Table 3$)$.

\section{Comparison of radiation dose}

Although there was no significant difference in CT signs and image quality between the study group and control group, the differences in CTDIvol, DLP, and ED between the two groups were statistically significant $(\mathrm{t}=31.14$, 27.73, 27.73, $p<0.01$, Table 4). The effective dose in the study group was reduced by $76 \%$ compared to the control group.

\section{Discussion}

The chest CT scan can be used for the follow-up of COVID-19 to guide clinical management [6]. COVID-19 has made rapid progress, and its imaging signs have changed greatly in different periods. Multiple chest CT examinations can help monitor the progression change of COVID-19 disease, which has important value in the follow-up of COVID-19 [7]. However, multiple CT follow-ups will increase medical exposure, which may exaggerate disease condition.

How to reduce the radiation dose under the premise of meeting the needs of the imaging diagnosis has been studied intensively in recent years. Among them, reducing the tube current is one of the main methods to reduce the radiation dose. Studies show that lowering the tube current can effectively reduce the $\mathrm{CT}$ radiation dose [8]. Chinese Medical Association experts have recommended $100 \sim 120 \mathrm{KV}$ and less than $30 \mathrm{mAs}$ as a new generation iterative algorithm of low-dose screening scheme CT [9]. $\mathrm{Hu}$ et al. have screened ground glass nodules in the lungs using the reference tube current of 30 mAs. They used CareDose 4D technology to automatically adjust the tube current according to the change of the thickness of the human body to obtain similar image quality for each layer [10]. Although lowdose scanning has been studied intensively, no personalized scanning method specifically for GGO and crazypaving pattern has been reported. In this study, we have applied a CareDose 4D scanning method combined Karl $3 \mathrm{D}$ iterative reconstruction technology with a fixed 120 $\mathrm{kV}$ and reference tube current of $30 \mathrm{mAs}$ for the followup of COVID-19 patients. We have used Karl 3D iterative reconstruction technology in the study group, but not in the control group. If the control group of the lung window use karl 3D iterative reconstruction, the images will be too smooth, and the contrast will be reduced. Karl $3 \mathrm{D}$ is an iterative reconstruction technology of United Imaging Healthcare (UIH), which found that image quality is limited by conventional filtered back projection (FBP) imaging reconstruction technique. By $\mathrm{FBP}$, noise in reconstruction images obviously increases 

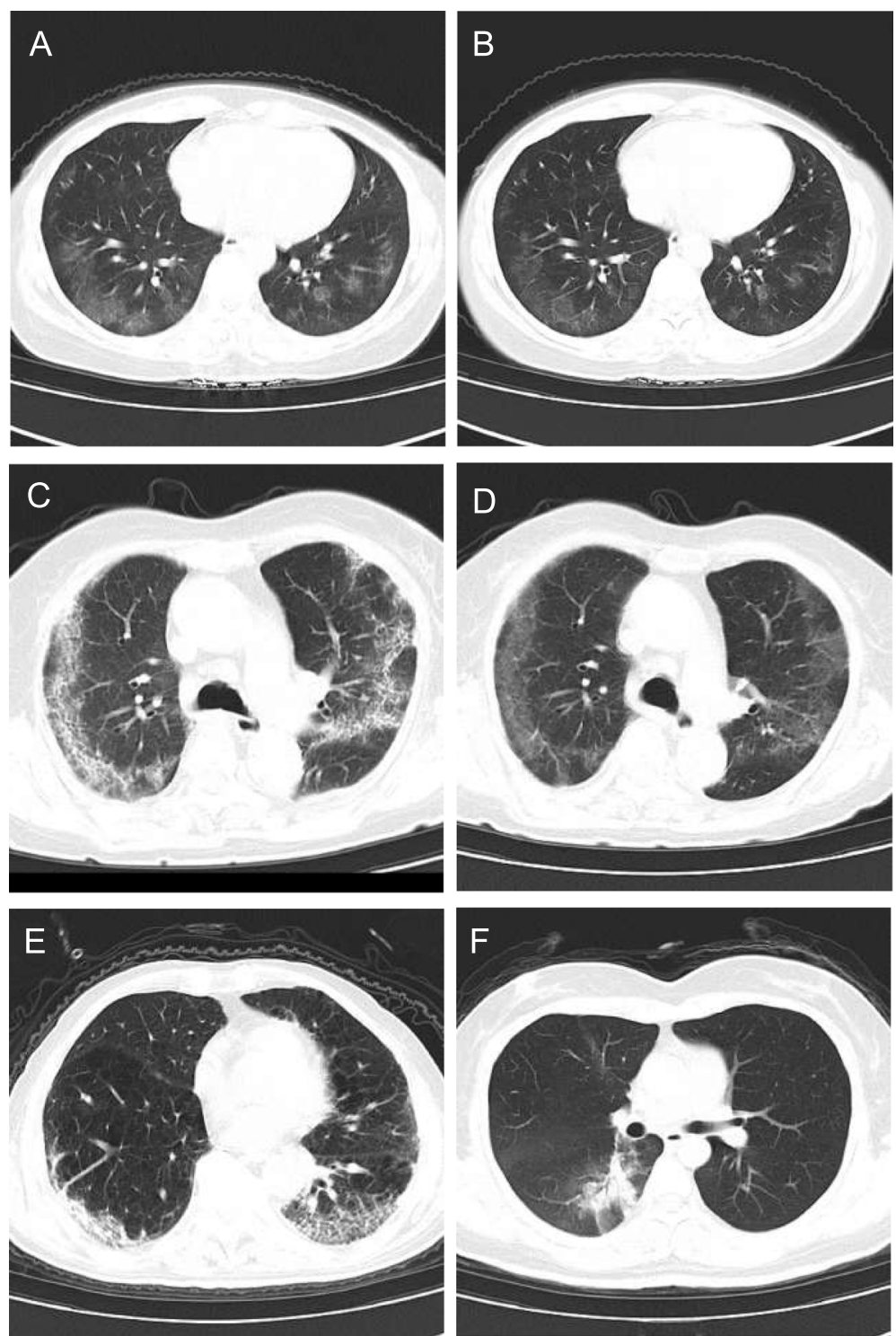

Fig. 1 CT images using CareDose 4D combined with Karl 3D technology in the low dose for the follow-up of COVID-19. (A-B) CT images of a 43year old female. Follow-up with low-dose CT (Fig. A) showed that the lower lobe of the lungs is scattered with thin GGO and the edges are blurred. Tube voltage is $120 \mathrm{kV}$ and tube current is $29 \mathrm{~mA}$. After 5 days, follow-up with conventional dose CT (Fig. B), showed slightly absorbed sub-pleural GGO compared to Fig. A. Tube voltage is $120 \mathrm{kV}$ and tube current is $20 \mathrm{~mA}$. (C-D) CT images of a 81-year old female. Follow-up with conventional dose $C T$ (tube voltage of $120 \mathrm{KV}$ and tube current of $131 \mathrm{~mA}$ ) curved grid-like shadows can be seen under the pleura of both lungs, showing crazy-paving pattern (Fig. C), followed by low-dose CT (tube voltage of $20 \mathrm{kV}$ and tube current of $31 \mathrm{~mA}$ ) follow-up 2 weeks (Fig. D), The symptoms are not obvious, and the arc GGO changes. (E) CT image of a 64-year old male. Low-dose CT follow-up of clearly showed that the lower lobe subpleural crazy-paving pattern and the right lower lung was partially consolidated. (F) CT image of a 38-year old female. Tube voltage $120 \mathrm{kV}$, tube current 43mAs. Follow-up with low-dose CT showed flaky consolidation in lower lobe of right lung. Dissipative GGO was seen in the surrounding area. Tube voltage is $120 \mathrm{kV}$ and tube current is $33 \mathrm{~mA}$

Table 2 Comparison of the incidence of CT signs (\%)

\begin{tabular}{llllll}
\hline CT signs & GGO & Consolidation & Crazy-paving pattern & Fibrous cord shadow & Axial interstitial thickening \\
\hline Control group & $26(86.7)$ & $23(76.7)$ & $21(70)$ & $14(46.7)$ & $3(10)$ \\
Study group & $24(80)$ & $21(70)$ & $20(66.7)$ & $14(46.7)$ & $4(13.3)$ \\
$x^{2}$ value & 0.48 & 0.34 & 0.077 & 0.00 & 0.16 \\
$p$ value & 0.49 & 0.56 & 0.78 & 1.00 & 0.69 \\
\hline
\end{tabular}


Table 3 Comparison of subjective score, $C T$ value, and SD value of descending aorta

\begin{tabular}{llll}
\hline & Subjective score & Descending aortic CT value & SD \\
\hline Control group & $4.27 \pm 0.78$ & $36.03 \pm 5.78$ & $7.27 \pm 0.42$ \\
Study group & $3.97 \pm 0.81$ & $38.06 \pm 5.73$ & $7.44 \pm 0.29$ \\
$t$ value & 1.46 & -1.37 & -1.86 \\
$p$ value & 0.15 & 0.17 & 0.07 \\
\hline
\end{tabular}

Note: Subjective score, descending aortic CT value, and SD value are expressed as $x \pm s$

as radiation dose decreases, which impacts diagnostic confidence. In order to effectively reduce radiation dose while ensuring the accuracy of diagnosis, Karl 3D iterative reconstruction technology has been developed by $\mathrm{UIH}$, which can greatly reduce the image noise caused by low-dose scanning and effectively improve the image quality [11]. We found that there was no statistically significant difference in the objective scores of overall image quality between the study group and control group. However, significant differences were found in CTDIvol, DLP and ED radiation dose indexes between the two groups. The effective dose in the study group $(1.22 \pm 0.14 \mathrm{mSv})$, which was reduced by about $76 \%$, was much lower than that of the control group $(5.05 \pm 0.74$ $\mathrm{mSv})$.

Previous studies have shown that the CT image results showed that small patchy GGOs are usually found to be localized at the pleura, unilateral or lower lung lobe at early stage of COVID-19 [12]. As the disease progresses, GGO will increase and some consolidations and gridlike changes may also occur. Two weeks later, the lesions are gradually absorbed. The density, scope and number of lesions is reduced. Only a little thin GGO and fiber strand shadows remain. During the early GGO progress, the density increases and the interlobular septal thickening forms a grid-like shadow, which is the crazy-paving pattern $[13,14]$. We used GGO and crazypaving pattern as the image evaluation criteria for two main reasons. One is that these two signs are important CT signs of COVID-19, and the occurrence rate is high. The second is that the GGO contrast is low and close to normal lung tissue. It is difficult to observe the lesion clearly when the image noise is increased [15]. The main CT signs of COVID-19 include GGO, consolidation, crazy-paving pattern, and fiber strands, etc. But axial interstitial thickening is rare. It may be related to the

Table 4 Comparison of radiation dose $(x \pm s)$

\begin{tabular}{llll}
\hline & CTDI $I_{\text {vol }}(\mathrm{mGy})$ & $\mathrm{DLP}(\mathrm{mGy} . \mathrm{cm})$ & $\mathrm{ED}(\mathrm{mSv})$ \\
\hline Control group & $11.21 \pm 1.50$ & $360.50 \pm 52.99$ & $5.05 \pm 0.74$ \\
Research group & $2.53 \pm 0.27$ & $87.25 \pm 10.21$ & $1.22 \pm 0.14$ \\
$t$ value & 31.14 & 27.73 & 27.73 \\
$p$ value & 0.00 & 0.00 & 0.00 \\
\hline
\end{tabular}

Note: CTDIvol, DLP and ED are expressed as $\mathrm{x} \pm \mathrm{s}$ fact that the lesion is easy to involve the peripulmonary interstitium and less axial interstitial tissue. We found that the incidence of the above signs was similar and there was no statistical difference between the two groups. In our study, the subjective scores of the image quality of the two groups were $\geq 3$, with no statistical difference. Also, there was no significant difference in the $\mathrm{SD}$ value between the two groups. Although the image quality of the study group was slightly lower than that of the control group, it meets the imaging diagnostic requirements. The high incidence of multiple signs in this study indicates that the disease progresses rapidly, and signs often coexist in multiple periods.

We have noticed that there are some limits in our study. For example, the small sample size may lead to biased statistical analysis results. Also, only a set of lowdose scanning protocols has been established. Further experiments are required for a multi-parameter controlled study, which will make our conclusion more solid.

\section{Conclusion}

Our finding suggests that it is feasible to follow up patients with COVID-19 using the method of CareDose 4D combined with Karl 3D technology in the low dose computerized tomography. Under the condition of ensuring the image quality, the radiation dose is reduced to a great extent.

\section{Abbreviations}

CT: Computed tomography; COVID: Coronavirus disease; SD: Standard deviation; CTDIvol: CT dose index; DLP: Dose length product; ED: Effective dose

\section{Acknowledgements \\ Not applicable.}

\section{Authors' contributions}

$J L, X W, G L$, and $X X$ designed research; $J L, X W, X H, F C, X Z$, and $Y L$ analyzed and interpreted patients data regarding the COVID-19 disease; $J L$ and XW performed $\mathrm{CT}$ scan and data collection; $\mathrm{L}, \mathrm{XW}, \mathrm{GL}$, and XX wrote the manuscript. The authors read and approved the final manuscript.

\section{Funding \\ Not applicable.}

Availability of data and materials

The full data sets used and analyzed during the current study are available on reasonable request from the corresponding authors. 


\section{Ethics approval and consent to participate}

This prospective observational study was approved by the Institutional Review Board of China Resources \& WISCO General Hospital. Informed consent was waived by the review board due to the observational nature of the study and the epidemic of COVID-19 as an emergency public health event.

\section{Consent for publication}

Not applicable.

\section{Competing interests}

The authors declare that they have no competing interests.

\section{Author details}

'Department of Radiology, China Resources \& WISCO General Hospital, Wuhan 430080, China. ${ }^{2}$ Department of Biochemistry and Molecular Biology, China Medical University, Shenyang 110122, China. Institute of Translational Medicine, China Medical University, Shenyang 110122, China.

Received: 2 April 2020 Accepted: 13 May 2020

Published online: 24 May 2020

\section{References}

1. Wang C, Horby PW, Hayden FG, et al. A novel coronavirus outbreak of global health concern. Lancet. 2020;395:470-3.

2. Dhungana HN. Comments on "preliminary estimation of the basic reproduction number of novel coronavirus (2019-nCoV) in China, from 2019 to 2020: a data-driven analysis in the early phase of the outbreak". Int J Infect Dis. 2020;94:72-3.

3. Li Y, Yongsheng L. Identification and management strategy of COVID-19's critically ill patients. New Medicine. 2020;51(03):161-7.

4. $\quad$ Bing $L, M a ~ S$, Xiaodong $L$, et al. Experimental studies on injury effects of repeated computed tomography scan in mice. Chin J Radiol Med Prot. 2014;34(03):164-7. https://doi.org/10.3760/cma.j.issn.0254-5098.2014.03.002.

5. Lu X, Gong W, Wang L, Li L, Xie B, Peng Z, et al. Clinical features and high resolution $C T$ imaging findings of preliminary diagnosis novel coronavirus pneumonia. Chin J Radiol. 2020;54(04):296-9. https://doi.org/10.3760/cma.j. cn112149-20200204-00085.

6. Zu Z, Jiang M, Xu P, Chen W, Ni Q, Lu G, et al. Coronavirus Disease 2019 (COVID-19): A Perspective from China. Radiology. 2020;200490. https://doi. org/10.1148/radiol.2020200490.

7. Chinese Society of Radiology, Chinese Medical Association. Radiological diagnosis of COVID-19: expert recommendation from the Chinese Society of Radiology (First edition). Chin J Radiol. 2020;54(04):279-85. https://doi.org/ 10.3760/cma.j.cn112149-20200205-00094.

8. Feng ZHAO, Yong-ming ZENG, Gang PENG, Hui-zhi CAO, Jing-min LIAO, Ren-qiang YU, et al. Correlation between the tube current and image noise in low-dose chest CT scan. Chin J Radiol Med Prot. 2012;32:100-3.

9. Chinese Society of Radiology. Expert consensus on imaging of pulmonary subsolid nodules. Chin J Radiol. 2015;49:254-8.

10. Hu S, Peng Z, He C, Haomiao Q, Tao Z, Yubiao P, et al. Phantom study of the influence of CareDose 4D and care kV on CT pulmonary ground glass nodule with respect to image quality and radiation dose. Chin J Radiol Med Prot. 2019;39:534-8.

11. Zhu L, Hui Z. Effect of Karl 3D iterative reconstruction technique on the image quality of the chest low-dose CT. J Prac Radiol. 2017;33:280-2.

12. Pan F, Ye T, Sun P, Gui S, Liang B, Li L, et al. Time Course of Lung Changes On Chest CT During Recovery From 2019 Novel Coronavirus (COVID-19) Pneumonia. Radiology. 2020;200370. https://doi.org/10.1148/radiol. 2020200370.

13. Chung M, Bernheim A, Mei X, et al. CT imaging features of 2019 novel coronavirus (2019-nCoV). Radiology. 2020;295:202-7.

14. Bernheim A, Mei X, Huang M, Yang Y, Fayad Z, Zhang N, et al. Chest CT Findings in Coronavirus Disease-19 (COVID-19): Relationship to Duration of Infection. Radiology. 2020;200463. https://doi.org/10.1148/radiol.2020200463.

15. Andreas $C, M C L, A C Y$, et al. $C T$ patterns of fungal pulmonary infections of the lung: comparison of standard-dose and simulated low-dose CT [J]. Eur J Radiol. 2012;81:2860-6.

\section{Publisher's Note}

Springer Nature remains neutral with regard to jurisdictional claims in published maps and institutional affiliations.
Ready to submit your research? Choose BMC and benefit from:

- fast, convenient online submission

- thorough peer review by experienced researchers in your field

- rapid publication on acceptance

- support for research data, including large and complex data types

- gold Open Access which fosters wider collaboration and increased citations

- maximum visibility for your research: over $100 \mathrm{M}$ website views per year

At $\mathrm{BMC}$, research is always in progress.

Learn more biomedcentral.com/submissions 